\title{
MORPHOLOGICAL VARIATION OF LEAF PATTERN OF THE NEPALESE TARAXACUM SPP. (ASTERACEAE)
}

\author{
Sanjeev Luintel ${ }^{1 *}$, Sabina Gyawali ${ }^{1}$, Babu Ram Paudel ${ }^{2,3}$, Mani Shrestha ${ }^{4,5}$, Lokesh Ratna \\ Shakya ${ }^{1}$ \\ 1 Amrit Science College, Tribhuvan University, Lainchaur, Kathmandu, Nepal \\ 2 Laboratory of Ecology and Evolutionary Biology, Yunnan University, 2\# North, Cuihu Road, \\ Kunming, 650091, Yunnan, China \\ 3 Department of Botany, Prithvi Narayan Campus, Tribhuvan University, Pokhara, Nepal \\ 4 School of Media and Communication, RMIT University, Melbourne, VIC 3001, Australia \\ 5 Faculty of information Technology, Monash University, Melbourne, VIC 3800, Australia \\ *Author for correspondence: luintelsanjeev234@gmail.com (SL)
}

\begin{abstract}
Morphological variation of leaf pattern is very common in flowering plants to non-flowering plants that were used to differentiate the species in genus to species level. In this study, we used leaf morphology as the key characters to separate the species of Nepalese Taraxacum. Samples were collected from different parts of Nepal and herbarium specimen were observed to find the variation between the different species of Taraxacum. Our study shows that the presence of two distinct group in this genus Taraxacum. Taxa one is characterized by leaf with double margin (e.g. Taraxacum eriopodum along with 3 other species) and another group is characterized by leaf with single margin (e.g. Taraxacum tibetanum along with 5 other species).
\end{abstract}

Keyword: Morphology, leaf, taxonomy, venation

\section{INTRODUCTION}

The genus Taraxacum F.H.Wigg is the largest genus in the family Asteraceae that consists of 2814 species worldwide (APG-III 2009) and 14 species in Nepal (Hara et al 1976, Press et al, 2000). Genus Taraxacum lies in sub tribe Crepidinae under tribe Cichorieae of sub family Cichoriodeae (APG-III 2009, Xuejun Ge et al 2011). Mostly the species are distributed in the arctic and temperate zones of the northern hemisphere, with main diversity in mountains of Eurasia, a few species in temperate regions of the southern hemisphere (Xuejun Ge et al 2011). It is commonly called as 'dandelions' in the world.
In Nepal, the distribution of Taraxacum ranges from $720 \mathrm{~m}$ to $4850 \mathrm{~m}$ from east to west and from tropical region to alpine region (Malla 1976, Hara et al 1982, Polunin and Stainton et al 1984, Press et al 2000, Shrestha et al 2005, Xuejun Ge et al 2011). The distribution of many of the species is mainly concentrated on the central and western part than to the eastern region of Nepal.

Leaf pattern of flowering plants are studied around the world in terms of taxonomic identification, to understand the morphological variation based on different climate, to find out the size variation and so on. Leaf morphology is one of the most important visual part of 
angiosperm which varies on different species of flowering plants to non-flowering plants. Although general and floristic studies of Asteraceae have been carried out extensively, investigations are yet inadequate of the genus Taraxacum from Nepalese Himalaya (Soest, J. L. van. 1960). This is a complex family for the taxonomic study and identification. However, none of the work has been done yet in Nepal. In the absence of molecular data and inaccessibility of the modern tool, this study will concentrate on morphological variation of leaf characteristics, in solving the taxonomic problems of the genus Taraxacum of Nepalese Himalaya. The key characteristics of leaf variation has been prepared for identification of different species of Taraxacum.

\section{MATERIALS AND METHODS}

\section{Protologue and standard literature review}

Protologue, the original material associated with a newly published name, consisting the description or diagnosis and any of number of other elements such as illustrations, synonyms and related literature were reviewed. All these provide the nomenclatural accuracy and species identification easier and also clarify the major taxonomic problems within a group. Different Floras like Hooker, J.D, 1882 (Flora of India), Grierson et al 2001(Flora of Bhutan), Xuejun Ge et al 2011(Flora of China) along with published research articles were reviewed for the identification of the species. Herbarium specimens were studied for complete documentation of different species within the genus.

Sample plant collection and preparation of herbarium specimens

We collected different species of Taraxacum from different parts of the country (the plant species were collected from Panchase, Ghandruk,
Deurali, Ghorepani, Sikha, Jomsom, Muktinath, Parbatikunda, Dhunche to Gosainkunda starting from June to November 2017). Dried and perfect plant specimens were mounted on the standard size of herbarium paper $41.25 \mathrm{~cm} \mathrm{x}$ $28.75 \mathrm{~cm}$. Specimens were well mounted by using the glue, needle and thread. Small paper envelopes were attached to the sheet to hold seeds, extra flowers, or any part of the specimen. Unnecessary overlapping of leaves and other plant parts were removed.

\section{Identification of specimens}

The specimens were identified using standard literature (Van Soest 1961-63, Flora of Nepal, Hooker J.D 1882, Grierson et al 2001 and Xuejun Ge et al 2011) and further confirmed by examining with the herbarium deposited at National Herbarium Centre (KATH) and Tribhuvan University Herbarium (TUCH). Further, the plant specimens were also compared with the digital photographs of herbarium specimens of E (Royal Botanical Garden, Edinburg), BM (Bristish Museum, Digital image BM00003550, Taraxacum nepalense K (Royal Botanical garden ,Kew), TI (University Museum ,University of Tokyo), NHM (Natural Historical Museum ). The literatures available and the main protologue texts were consulted for the further identification and confirmation of the species.

\section{Morphological study}

The collected herbarium specimens, herbarium at KATH, TUCH and ASCOL (Amrit Science Campus) were studied under the dissecting microscope for the respective species of Taraxacum. Morphological characteristics were observed and recorded for the vegetative characters including size, shape, and venation on leaf, leaf margin, and lobes. To study details for some parts, we also used light microscope, and dissecting microscope. For studying the 
morphological characters, the plant parts were soaked in a detergent solution with ethanol and glycerol mixture in the ratio 1:10 which helps in the softening of the plants. The dissected vegetative parts were kept on a small paper envelope and attached on the sheet of the same respective herbarium specimens.

\section{Illustrations}

Free hand illustration of habit and leaf were made. Photographs of plants parts including vegetative parts of particular species were taken.

\section{RESULTS}

The leaves are simple, lobed, form a basal rosette above the central tap root and they are runcinate to pinnatisect (see table 1 and Fig. 1a, b). We found leaves are pinnately veined (Fig. 2 and3). Some species have pinnatisect to pinnatipartite leaf i.e Taraxacum lanigerum. All the leaves are found in the base so called rosullate. The shape of the leaves varies from species to species. Leaves are acute, lanceolate, obtuse or oblanceolate, subacute, subobtuse. The margin of leaves is entire, dentate, denticulate, and lanceolate. Taraxacum amabile have lanceolate type of margin whereas $T$. pseudostenoceras have denticulate type of margin. Most of the species have arachnoid or hairs at the base of the leaves and the petiole are unwinged (i. e. T. eriopodum) in many species and few are narrowly winged (i. e. T. elegans). In most of the species, acute or obtuse leaf apices can be found. Taraxacum lanigerum have sub-acute leaves whereas T. nepalense have sub obtuse leaf.

\section{Identification key for the genus Taraxacum based on leaf morphology}

1a. Leaf double margin --------- 2 (Taraxacum eriopodum, T.staintonii., T.mucronulatum, T.nepalense) 1b. Leaf single margin ------ 5 (T.tibetanum, T. parvulum, T. la nigerum, T. pseudostenoceras,T.sikkimense,T.mitalii)

2a. Margin entire, sparsely dentate --------- T. eriopodum

2b. Margin dentate -------- 3 (T.nepalense, T.staintonii, T.mucronulatum)

3a. Apex subobtuse mucronate ---------T.nepalense

3b. Apex subobtuse non mucronunate --------- 4 (T. mucronulatum, T. staintonii)

4a. Lateral lobes more than 5 ---------T.staintonii

4b. Lateral lobes 2-4 in number --------- T. mucronulatum

5a. Leaf apex narrowly acute -------- 6 (T. lanigerum, T. pseudostenoceras, T. mitalii, T. sikkimense)

5b. Leaf apex obtuse ---------9 (T. tibetanum, T. parvulum)

6a. Margin doubly dentate with 3 lobes ---------T. pseudostenoceras

6b. Margin dentate with more than 3 lobes ---------7 (T. lanigerum ,T. sikkimense ,T. mitalii)

7a. Leaf lobes strongly runcinate --------- T. sikkimense

7b. Leaf lobes 5 -------- 8 (T. lanigerum, T. mitalii)

8a. Lateral leaf lobes with recurved acute apex --------- T. lanigerum

8 b. Lateral leaf lobes with subacute apex --------- T. mitalii 


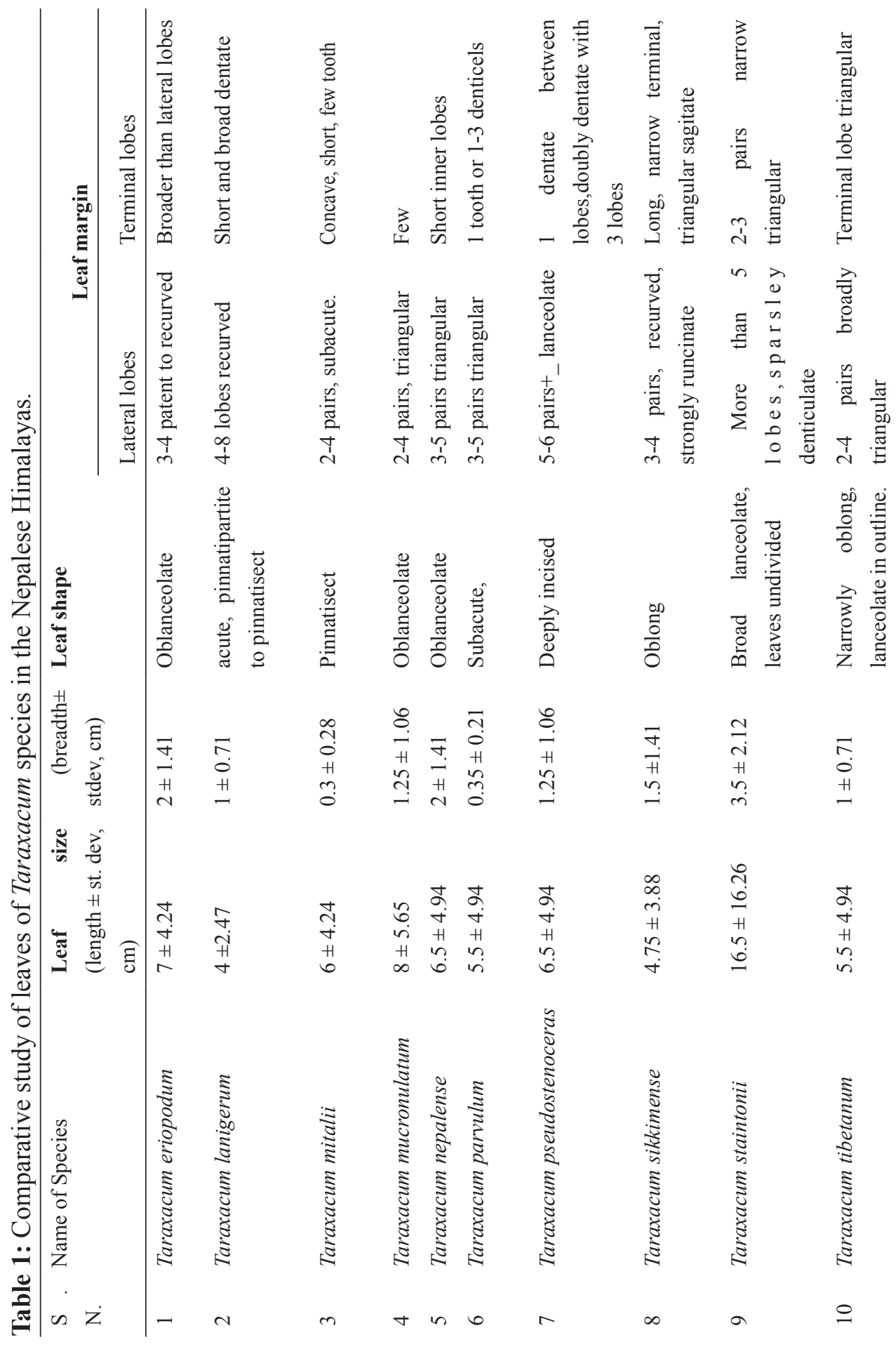


9a. Leaf blade dentate T.tibetanum

9b. Leaf blade lanceolate --------- T. parvulum
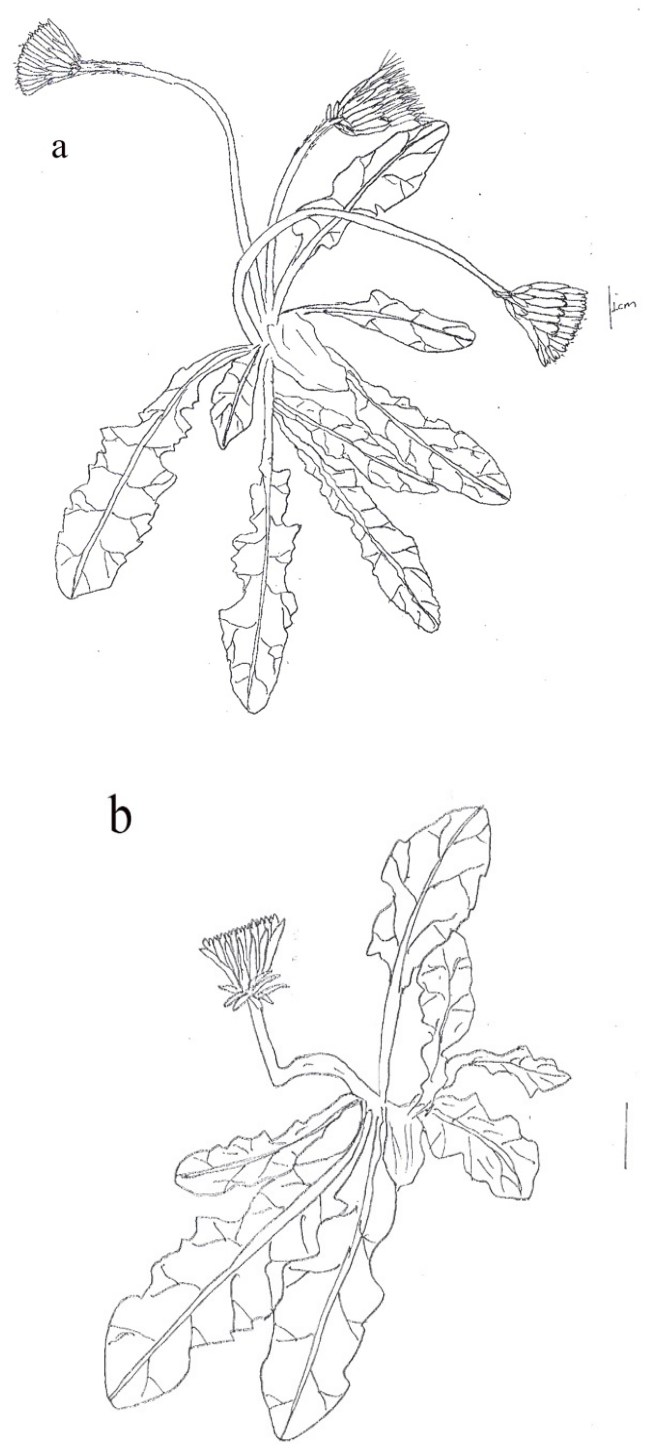

Figure 1. Example of habit sketch of Taraxacum eriopodum (a) and T. parvulum (b). Scale bar in the figure $\times 1 \mathrm{~cm}$.

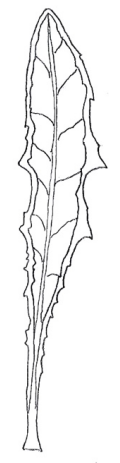

a

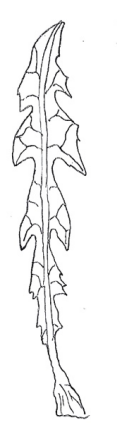

d

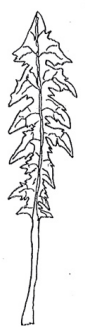

b
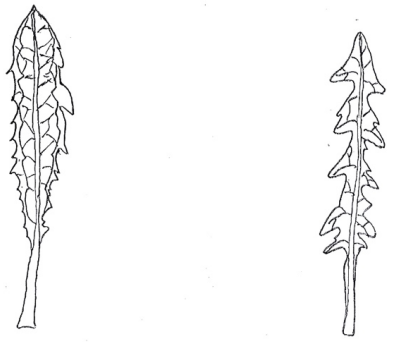

f

Figure 2. Diagrammatic sketch of leaf morphology of different species of Taraxacum. a. T. mucronulatum $(\times 1 \mathrm{~cm})$, b. T. lanigerum $(\times 1 \mathrm{~cm})$, c. T. pseudostenoceras $(\times 1 \mathrm{~cm})$, d. T.sikkimense $(\times 1 \mathrm{~cm})$, e.T. nepalense $(\times 1 \mathrm{~cm}), \mathrm{f}$. T.mitalii $(\times 1 \mathrm{~cm})$.

\section{DISCUSSION}

The present study demonstrates that leaf morphology could be used as a new taxonomic parameter to identify and distinguish Taraxacum species. The result shows that the species are mainly separated first from double and single leaf margin. Taraxacum eriopodum has entire margin with sparsely dentate whereas T. nepalense having subobtuse and mucronate apex. Taraxacum staintonii has lateral lobes more than 5 whereas $T$. mucronulatum has 2-4 lateral lobes. Taraxacum pseudostenoceras has 
margin doubly dentate with 3 lobes. Taraxacum sikkimense consists of leaf lobes strongly runcinate. The lateral lobes of T. mitalii has subacute apex whereas $T$. lanigerum has recurved acute apex. Taraxacum tibetanum has dentate leaf blade whereas T. parvulum has lanceolate leaf blade.

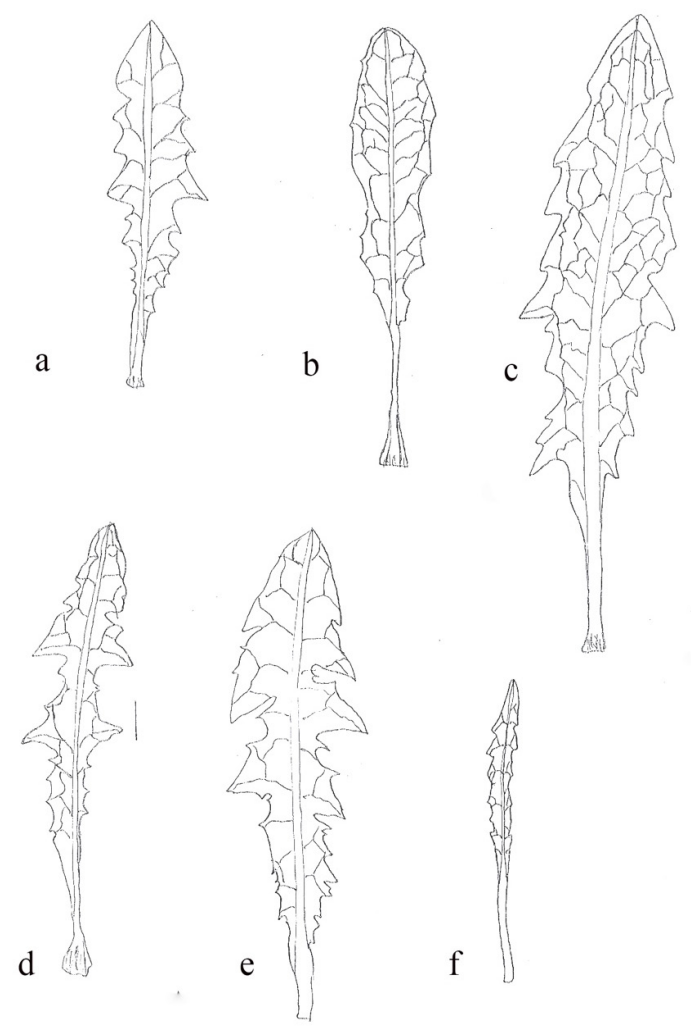

Figure 3. Diagrammatic sketch of leaf morphology of different species of Taraxacum. a. T. tibetanum $(\times 1 \mathrm{~cm})$, b. T.eriopodum $(\times 1 \mathrm{~cm})$, c. T.staintonii $\left({ }^{\prime} 2 \mathrm{~cm}\right)$, d. T.parvulum $(\times 1 \mathrm{~cm})$, e. Taraxacum parvulum $(\times 1 \mathrm{~cm})$, f. Taraxacum parvulum $(\times 1 \mathrm{~cm})$.

Leaf morphology has been used for identification of different species and understand the evolution of flowering plants (Jones et al 2009, Romitelli and Martins 2013). For example, Jones et al (2009) studied the leaf shape morphology of South African Pelargonium species and suggested that different suites of leaf structure were used to determine the variation and identification key for this species. Teruro (2013) and his team studied the difference in leaf morphology of Taraxacum species of native and exotic species in Japan and found that leaf size is inconclusive to use to separate the species. However, our current work is focused on how leaf morphological variation can be used to distinguish the plant species. Future work will concentrate to understand the other characteristics features of Taraxacum along with leaf morphology to separate Taraxacum species in Nepalese Himalayas.

\section{ACKNOWLEDGEMENTS}

We highly acknowledge Herbarium Centre KATH and TUCH for providing herbarium to study the genus Taraxacum deposited at the herbaria. We also thank Annapurna Conservation Area and Langtang National Park providing the permit to collect the sample of Taraxacum species. First author is thankful to Prabin Bhandari for providing the Taraxacum parvulum species herbarium.

\section{REFERENCES}

Grierson A. J. C. and D. G. Long (2001). Flora of Bhutan. Royal Botanical Garden Edinburgh and Royal Government of BhutanVol.2(3): 1578-1584.

Hara, H., A. O. Charter, and L. H. J. Williams, (1976). An enumeration of the flowering plants of Nepal 1:42. British Museum (Natural History), London.

Hooker, J.D. (1882). The Flora of British India Vol.III.401L.Reeve and Co., London

Jones, C.S., F.T. Bakker, C.D. Schlichting and A.B. Nicotra, (2009). Leaf shape evolution in the south African genus Pelargonium 1'Her.(Geraniaceae). Evolution, 63(2), pp. 479-497. 
Malla, T.B., S.B, Rajbhandari, T.B, Shrestha, P.R, Shakya, K.R. Rajbhandari (1976). Flora of Langtang.

Press, J. R., K.K., Shrestha and D.A. Sutton (2000). Annotated checklist of flowering plants of Nepal. The Natural History Museum, London.

Polunin, O., and A. Stainton (1984). Flowers of the Himalaya. Oxford University Press.

Romitelli, I. and M.B.G., Martins (2013). Comparison of leaf morphology and anatomy among Malva sylvestris (" gerânioaromático"), Pelargonium graveolens ("falsa-malva") and Pelargonium odoratissimum ("gerânio-de-cheiro"). Revista Brasileira de Plantas Medicinais, 15(1): 91-97.

Soest, J. L. van. (1960). New species of Taraxacum from Asia (includ. Rechingeri, Iter Iranicum II no. 40). Acta Bot. Need. 9; 302-326. 1961. New species of Taraxacum from the Himalayan Region; Bull. British Mus. (Nat. Hist.) Botan. 2. 10: 263-273

Xuejun Ge, Jan Kirschner and Jan Štěpánek (2011) Flora of China, Vol 21:270-325. Science Press, Beijing and Missouri Botanical Garden Press, St.Louis.

(Received 23 Nov 2017, revised accepted 20 Dec 2017) 